\title{
SISTEM INFORMASI ADMINISTRASI DESA DI KANTOR DESA SUMBERSEKAR
}

\author{
Meme Susilowati $^{1)}$, Dicky Chandra ${ }^{2)}$ \\ 1)2) Sistem Informasi Universitas Machung \\ E-mail:meme.susilowati@machung.ac.id 1),321310002@student.machung.ac.id ${ }^{2)}$
}

\begin{abstract}
Abstrak
Kantor Desa Sumbersekar merupakan kantor desa yang terletak di daerah Dau, Malang. Kantor desa ini bergerak pada bidang pelayanan masyarakat, seperti : Membuat Kartu Tanda Penduduk (KTP), membuat Kartu Keluarga (KK), dan membuat surat keterangan sesuai dengan keinginan warga, namun seiring berjalannya waktu Kantor Desa Sumbersekar mencetak surat dalam jumlah yang banyak, sehingga menyulitkan proses perekapan surat serta No. Kop surat yang masih direkap secara manual. Sehingga menyulitkan staf kantor desa untuk mencari No. Kop surat yang akan digunakan karena jumlah surat yang juga terhitung sangat banyak dan harus mencarinya di buku rekapan. Proses pembuatan surat juga masih menggunakan Microsoft Word, meskipun itu menggunakan teknologi komputer tetapi itu masih sangat menyulitkan karena menyetikan isi surat tersebut secara manual dan juga tehitung sangat banyak. Proses pelaporan operasional tahunan maupun bulanan juga masih dilakukan secara manual. Sehingga staf desa juga harus merekap menghitung jumlah surat yang keluar, surat yang gagal diterbitkan. Oleh karena itu, diperlukan sebuah sistem informasi administrasi desa yang dapat membantu pencatatan nomor surat, membantu pembuatan surat, perekapan surat, pembuata KTP maupun KK, serta sebuah fitur pelaporan yang lengkap sehingga memudahkan kinerja dari kantor desa tersebut sendiri.
\end{abstract}

\section{Kata kunci :}

Sistem Informasi, Operasional, Pelaporan, Perekapan.

\begin{abstract}
Sumbersekar Village Office is a village office located in Dau, Malang. This village office is engaged in the field of community services, such as: Make Identity Card (KTP), make a Family Card $(K K)$, and make a letter in accordance with the wishes of citizens, but over time Sumbersekar Village Office prints letters in large numbers, so complicate the process of recording the letter and no. Letterheads are still manually captured. Thus making it difficult for village office staff to find No. Letterheads will be used because of the number of letters that are also counted very much and have to look it up in a recap book. The process of making letters is still still using Microsoft Word, although it uses computer technology but it is still very difficult because it includes the contents of the letter manually and also counted very much. Annual and monthly operational reporting process is also still done manually. So the village staf must also calculate the number of outgoing letters, letters that fail to be issued. Therefore, a village administrative information system is needed to assist in the recording of letter numbers, assisting in the preparation of letters, the recording of letters, the establishment of KTP and $K K$, and a comprehensive reporting feature to facilitate the performance of the village office itself.
\end{abstract}

\section{Keywords :}

Information Systems, Operations, Reporting, Recognition

\section{Pendahuluan}

Desa Sumbersekar memiliki sejarah yang tidak terlepas dari sejarah Masyarakat Jawa di Kabupaten Malang. Desa yang tradisional, karena sangat terpengaruh oleh gaya kehidupan

masyarakat Jawa. Nama Sumbersekar didasarkan pada banyaknya sumber air bening yang ada di wilayah Desa Tlekung Kota Batu , yang di manfaatkan oleh warga Desa Sumbersekar. Adapun Kepala Desa yang pernah menjabat hingga sekarang adalah sebagai beriikut: Aris (jaman Belanda), Sarbini, Oentoeng Rahardjo, Bambang Sumantri, dan Supandri dan sekarang Hasan Asyari. (KIM Sumbersekar, 2015).

Berdasarkan latar belakang diatas dan didukung dengan observasi lapangan serta wawancara dengan Sekretaris Desa Bapak Rinda 
Perdana dan Kepala Desa Bapak Hasan Asyari, maka dirumuskanlah beberapa permasalahan yang ada perlu penanganan segera yaitu:

a. Bagaimana merancang dan membangun sistem informasi administrasi untuk meningkatkan layanan kepada warga desa terkait kebutuhan berbagai surat keterangan dari Kantor Desa.

b. No. Kop surat yang muncul secara otomatis dan berurutan.

c. Bagaimana membangun local e-government Desa Sumbersekar yang dimulai dari sistem backend.

d. Pencatatan No. Kop surat yang masih dalam bentuk berkas, sehingga menyulitkan staff kantor desa untuk mengurutkan ataupun menerbitkan No.Kop surat baru.

e. Pencatatan biodata registrasi warga yang masih dalam bentuk fotocopy KTP tidak tersistemasi.

f. Pengumpulan Dokumen Pelengkap seperti surat keterangan RT dan RW yang masih berbentuk hard copy yang diserahkan kepada staff kantor desa.

g. Pengumpulan Dokumen Utama seperti lunas PBB, KTP, KK dan dokumen lain yang disyaratkan oleh Kantor Desa ypang masih berbentuk hard copy yang diserahkan kepada staff kantor desa.

Dengan masalah yang telah dijabarkan di atas. Maka peneliti akan membuat sebuah sistem informasi administrasi desa kepada Kantor Desa Sumbersekar. Besar harapannya sistem yang akan dibuat ini akan berhasil dan mampu untuk membantu dan memudahkan kantor desa Sumbersekar dalam beroperasional.

\section{Tinjauan Pustaka}

Hasil penelitian dari peneliti sebelumnya : Sistem Pelayanan Administrasi Kependudukan Desa Candigatak Berbasis Web. Penelitian yang dilakukan Syarif Hidayatulloh, Cisde Mulyadi, Mahasiswa AMIK Cipta Darma Surakarta, mengembangkan sistem administrasi yang sudah ada di desa Candigatak, Sistem tersebut memberikan berbagai keuntungan antara lain dapat meminimalisir resiko kesalahan penulisan identitas, lebih praktis, dan lain-lain. Namun kelemahan sistem tersebut, warga tidak dapat dilayani secara 24 jam sesuai dengan motto Kepala Desa. Hal ini dikarenakan untuk mengakses sistem tersebut harus datang langsung ke kantor Kepala Desa, sementara jam kerja pemerintah Desa Candigatak hanya 5 hari dan terbatas. Sistem tersebut juga masih memiliki beberapa masalah yang sangat perlu untuk diatasi, yakni tidak dapat memproses mutasi kelahiran penduduk serta menampilkan arsip tentang surat pengantar KTP dan KK yang pernah diproses. Hal ini mendorong penulis untuk mencoba membuat sistem pelayanan adminsitrasi kependudukan berbasis web yang dapat diakses warga kapanpun, dimanapun, yang

juga dapat untuk mengolah mutasi kependudukan dan menampilkan arsip berbagai surat yang pernah diproses, sehingga akan memudahkan warga desa Candigatak dan meningkatkan kinerja Pemerintah Desa Candigatak.

\subsection{Three Major Phases}

Menurut Kendall \& Kendall (2012) Three Major Phases merupakan tiga tahap utama yang bertujuan merencanakan dan mengontrol proyek yang akan dibangun agar berhasil dilaksanakan. Ketiga tahap utama tersebut adalah analisis, desain dan implementasi. Pada tahap analisis, kegiatan yang dilakukan adalah mengumpulkan data, alur data dan analisis keputusan, dan persiapan prososal. Pada tahap desain, kegiatan yang dilakukan adalah mendesain data inputan yang diperlukan, desain input dan output dan pengaturan data. Sedangkan pada tahap implementasi dibagi menjadi dua kegiatan yaitu implementasi dan evaluasi.

\subsection{Unified Modeling Language}

Menurut Farid Azis (2005) Unified Modeling Language (UML) adalah sekumpulan simbol dan diagram yang digunakan untuk memodelkan software. Dengan UML, desain software dapat diwujudkan dalam bentuk simbol dan diagram. Desain dalam bentuk simbol dan diagram kemudian dapat diterjemahkan menjadi kode program. Implementasi kode program dari diagram UML dapat menggunakan bahasa pemrograman apa pun dengan syarat bahasa

pemrograman tersebut harus mendukung pemrograman berorientasi objek (OOP).

\subsection{Workflow Diagram}

Menurut Barbara (2009) workflow diagram secara visual mendetailkan satu atau lebih proses bisnis untuk memperjelas pemahaman atau membuat rekomendasi

perbaikan proses. Workflow diagram menunjukkan bagaimana pekerjaan diselesaikan, termasuk urutan bagaimana pekerjaan tersebut diselesaikan, menampilkan alur informasi melalui proses dan bagaimana orang bisnis dan 
agen eksternal terlibat di dalam proses. Oleh karena itu, workflow diagram merupakan salah satu teknik pertama yang perlu dipelajari seorang analis pemula. Workflow diagram merupakan teknik yang paling fleksibel dengan sedikit aturan dalam pembuatannya. Fleksibilitas

workflow diagram memungkinkan penggunaannya untuk berbagai jenis proyek. Penggunaan workflow diagram biasanya digunakan untuk implementasi atau perubahan kebutuhan seperti prosedur manual pegawai, standar prosedur operasional, dan menjabarkan rencana agar lebih mudah dipahami dibandingkan menggunakan teks tertulis.

\section{Metode Penelitian}

\section{Dalam Pengembangan Sistem Informasi digunakan sebuah metodologi pengembangan sistem untuk mempermudah upaya dalam membangun sebuah sistem yang baik. Dalam pengembangan sistem informasi, metodologi yang digunakan adalah Three Major Phases atau tiga aktivitas utama yang terdapat dalam setiap metodologi pengembangan sistem. Berikut merupakan alur pengerjaan dan tahapan Three Major Phases yang digunakan dalam penelitian ini.}

(1) Alur Pengerjaan

\section{a. Studi Lapangan}

Pada metode ini peneliti melakukan pengamatan langsung di Kantor Desa Sumbersekar. Selama menjalankan metode ini, peneliti jadi lebih mengerti mengenai proses bisnis yang ada, menemukan informasi yang nantinya diperlukan untuk analisis serta mengetahui apa saja masalah dan

kebutuhan dari Kantor

Desa Sumbersekar.

b. Studi Kepustakaan

Studi kepustakaan adalah metode pengumpulan data dengan cara membaca, mencari, memahami, serta meringkas hal-hal yang berhubungan dengan penelitian ini. Adapun sumber yang digunakan dalam metode ini adalah buku dan media online seperti website dan jurnal online. Metode ini digunakan untuk mengetahui landasan teori, langkah analisis dan desain, dan data yang akan dianalisis.

(2) Tahapan Three Major Phases

a. Analisis

Pada tahap analisis yang dilakukan adalah mengumpulkan data, alur data dan analisis keputusan, dan persiapan prososal. Peneliti megumpulkan data dengan melakukan pengamatan langsung dan wawancara dengan sekretaris desa. Dari kegiatan tersebut didapatkan alur proses bisnis yang dapat dijadikan sebagai acuan untuk mendesain alur data dalam sistem yang diusulkan. Sedangkan persiapan

proposal dilakukan dengan mengajukan seminar proposal dengan judul penelitian ini.

b. Desain

Pada tahap desain kegiatan yang dilakukan adalah membuat rancangan atau desain yang berdasarkan hasil

analisis yang telah dilakukan sebelumnya, diantaranya desain data inputan yang diperlukan, desain input dan output, serta pengaturan data. Berdasarkan alur data yang telah dianalisis, maka dibuat suatu desain data inputan apa saja yang dibutuhkan dalam sistem serta tampilan form input dan output. Pengaturan data yang dilakukan peneliti yaitu dengan membuat desain ERD.

c. Implementasi

Pada tahap implementasi, ada dua kegiatan yang dilakukan yaitu

implementasi dan evaluasi. Implementasi dilakukan dengan mengimplementasikan hasil dari analisis yang telah dilakukan dalam sebuah aplikasi online berbasis web, sedangkan evaluasi akan dilakukan apabila berdasarkan hasil respon dari penggunaan sistem dari pihak Kantor Desa Sumbersekar ataupun dosen penguji seminar hasil.

\section{Hasil dan Pembahasan}

\subsection{Implementasi}

Pada sub bab implementasi halaman akan dijelaskan hasil dan pembahasan dari pengembangan sistem informasi administrasi desa pada kantor desa Sumbersekar. Adapun hasil dari pengembangan sistem tersebut adalah sebagai berikut.

\subsubsection{Use Case Sistem}

Use Case sistem terdiri dari 4 aktor, yaitu: Staff desa, warga, kepala desa, kepala RT/RW. Masing-masing aktor memiliki wewenang sendiri-sendiri terhadap sistem dan 
dibatasi sesuai dengan hak akses dari aktor tersebut. Seperti digambar dibawah ini, merupakan usecase dari Staff desa, staff desa bisa mengonfirmasi kepada warga bahwa surat sudah selesai dicetak, melihat list permintaan surat dari warga, mencetak surat yang diminta oleh warga, mengakses repository, memvalidasi dokumen-dokumen yang diunggah oleh warga.

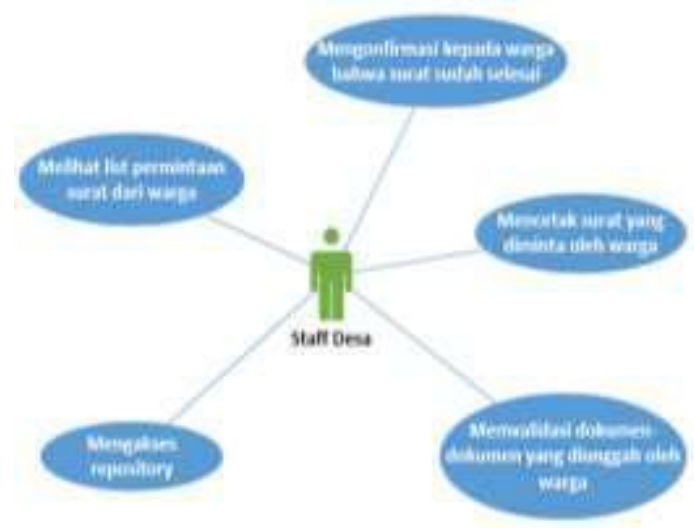

Gambar 4.1 Use Case Sistem Staff Desa

Use Case Warga, pada sistem ini warga bisa mengunggah dokumen pengantar, download surat keterangan, memilih jenis surat yang ingin dicetak oleh warga.

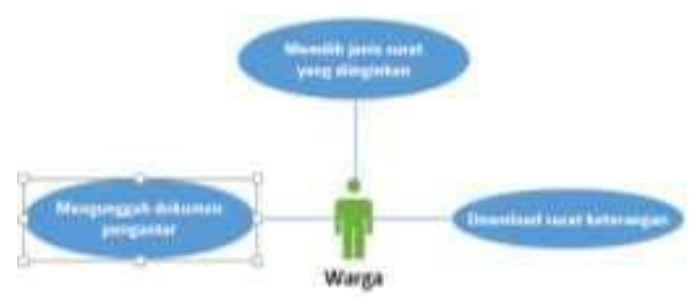

Gambar 4.2 Use Case Sistem Warga

Use Case Kepala desa pada sistem ini bisa memvalidasi surat yang sudah yang dicetak, dan bisa melihat rekapan laporan tentang surat yang sudah diterbitkan oleh kantor desa.

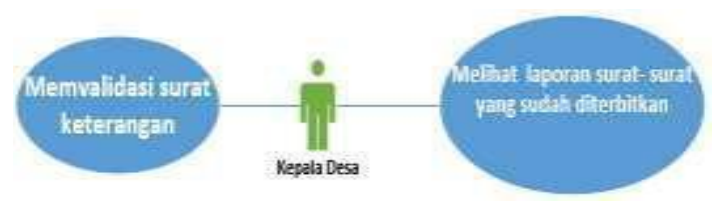

Gambar 4.3 Use Case Sistem Kepala Desa

Use Case Kepala RT/RW pada sistem ini hanya bisa untuk melihat rekapan laporan mengenai surat-surat yang sudah diterbitkan oleh kantor desa.

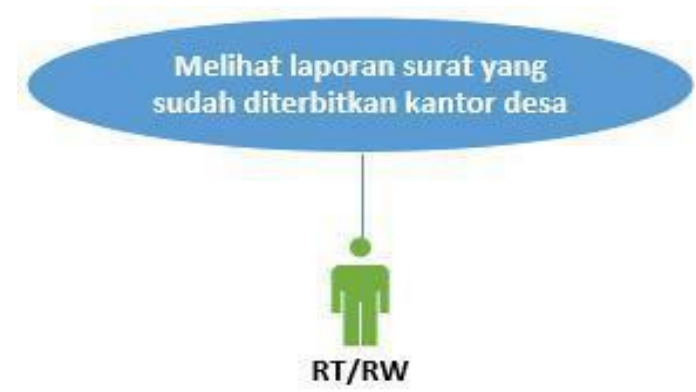

Gambar 4.4 Use Case Sistem Kepala RT/RW

\subsection{Work Flow Sistem}

Berikut adalah workflow dari sistem admintrasi kantor desa Sumbersekar Dau, dan workflow itu sendiri terdiri dari berbagai proses, yaitu: warga melakukan login ke sistem, kemudian mengisi form biodata, lalu mengonfirmasi biodata yang telah diisi, dan menggungah dokumen utama dan dokumen pelengkap ke sistem, lalu memilih jenis surat yang ingin dicetak, dan mengumpulkan permintaan pembuatan surat kepada staff desa di tempt, setelah itu warga bisa pulang dan tinggal menunggu konfirmasi dari kantor desa kapan surat tersebut akan selesai.

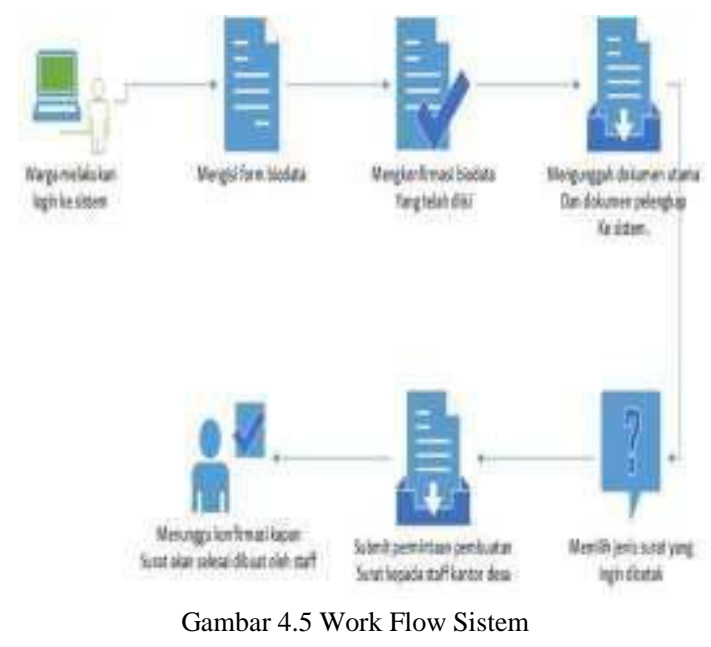

\section{Kesimpulan dan Saran}

Berdasarkan pelaksanaan kegiatan tugas akhir ini dapat diambil beberapa kesimpulan sebagai berikut:

- $\quad$ Sistem yang dibangun bisa membantu kantor desa dalam pembuatan surat keterangan yang diminta oleh warga desa.

- Sistemyangdibangunmampu memberikan notifikasi mengenai permintaan surat yang diminta oleh warga. 
- Sistem yang dibangun mampu menampilkan dan mencetak Kartu Tanda Penduduk (KTP) dan Kartu Keluarga (KK).

- Sistem ini dapat menampilkan laporan mengenai jumlah surat yang telah dicetak, dapat difilter sesuai bulan, tahun, dan jenis surat yang dipilih

- Sistem ini juga dapat menampilkan dashboard berbentuk grafik yang digunakan untuk memberikan informasi kepada tingkat eksekutif secara akurat, mudah, dan cepat

-

Saran yang diberikan oleh peneliti, untuk pengembangan sistem selanjutnya adalah pengembangan di bagian notifikasi, misalnya dengan menambahkan fitur SMS gateway, untuk menginformasikan kepada warga dan juga kepala desa akan surat yang telah selesai dicetak maupun surat yang membutuhkan validasi dari kepala desa.

\section{Daftar Pustaka}

[1] Adi Nugroho, Rekayasa Perangkat Lunak Menggunakan UML dan Java, Penerbit Andi, Yogyakarta, 2009.

[2] Bambang Wahyudi, SKom., MMSI, Perancangan Sistem, (Online), 2 April 2008 (http://www.google.co.id/perancis.doc, diakses 18 September 2016).

[3] Bangun Budiarto, dkk, Perancangan Sistem Informasi Manajemen Stok Makanan dan Minuman pada Restoran NZIP, dipresentasikan pada Seminar Nasional Teknologi Informasi dan Multimedia 2016, Yogyakarta, 6-7 Februari 2016.

[4] Barbara A.C., Seven Steps to Mastering Business Analysis, J. Ross Publishing, 2009.

[5] Evi Triandini dan I Gede Suardika, Step by Step Desain Proyek Menggunakan UML, Penerbit Andi, Yogyakarta, 2012.

[6] Farid Azis, Object Oriented Programming dengan PHP 5, Elex Media Komputindo, Jakarta, 2005.

[7] Jogiyanto, Sistem Teknologi Informasi edisi 3, Penerbit Andi, Yogyakarta, 2009.

[8] John Satzinger, Sistem Analysis and Design in a Changing World, 7th ed, Cengage Learning, 2015.

[9] Kendall \& Kendall., Sistem Analysis and Design, 8th ed, Pearson Educations, New Jersey, 2012.
[10] Syarif Hidayatulloh, Cisde Mulyadi, Sistem Pelayanan Administrasi Kependudukan Desa Candigatak Berbasis Web 2014.

[11] Kristiyana Sri Rahayu, Sistem informasi administrasi kependudukan di Desa MojoTengah Kecamatan Kedu Temanggung Menggunakan Visual Basic dan SQL Server, 2010. 